\title{
Livelihood Security Vis-à-Vis Perception towards Extreme Weather Events among Farmers Engaged in Different Farming Enterprises in Sundarbans Region of India
}

\author{
Asif Mohammad* and Anupam Chatterjee \\ Eastern Regional Station, ICAR-National Dairy Research Institute, Kalyani, India \\ *Corresponding author
}

\section{A B S T R A C T}

\begin{tabular}{l} 
K e y w o r d s \\
$\begin{array}{l}\text { Livelihood security, } \\
\text { Perception level, } \\
\text { Farm enterprise } \\
\text { combination, } \\
\text { Extreme weather } \\
\text { events }\end{array}$ \\
Article Info \\
Accepted: \\
$\begin{array}{l}\text { 15 November } 2020 \\
\text { Available Online: } \\
10 \text { December } 2020\end{array}$ \\
\hline
\end{tabular}

\section{Keywords}

Livelihood security, Perception level,

Extreme weather

\section{Article Info}

Accepted:

Available Online:

December 2020

\begin{abstract}
Prolonged extreme weather event can hamper the livelihood option of farming community especially the small and marginal farmer. Sundarbans region of India is one of the places in India where farming community face extreme weather events like floods, cyclone in almost every year. Adhering to only one farming enterprise may not secure sustainable livelihood of farming community. Moreover, perception of farming communities towards extreme weather should be analyzed for formulating future developmental projects in Sundarbans region. The study was conducted in two blocks of Sundarbans region of West Bengal by involving 150 respondents who were practicing three different enterprise combinations. It was found from the study that, respondents who were practicing the animal husbandry and horticulture enterprise combination had a high level of perception score as well as medium to high level of livelihood security score. On the contrary, animal husbandry and crop farming enterprise combination gave the lowest score pertaining to a livelihood security level as well as perception level. From the study, it was observed that livelihood security scores and perception level scores of the respondents were highly correlated.
\end{abstract}

\section{Introduction}

Extreme weather events create destruction of farming activities as well as the livelihood among the farming community. More frequent and intense extreme weather events would impact upon the ability of farming systems to maintain or increase levels of food production (Osborne and Evans, 2019). Resilience against extreme weather events getting more and more importance in modern day agriculture as incidences of extreme weather events are becoming very common place in the changing global climate conditions (Mohammad and Chatterjee, 2018). Sunderban region of India is one of the places where regular floods and cyclonic storms create enormous loss of economic activities and deteriorate the farming activities in the long run. One of the major sources of uncertainty in Indian agriculture is due to uncertain weather conditions (Mohammad et al., 2018). Recurrent extreme weather events can hinder adaptive capacities of people in 
low income countries that often have poor infrastructure and poor access to basic services (Patel et al., 2019).Financial security was directly linked to ability to cope with the extreme weather events (Paltasingha and Goyarib, 2015). In this circumstance cultivating only one type of crop or engaged oneself in farming one type of farming system can enhance the possibility of economic losses more. Agricultural crop farming can be ravaged due to saline water inundation and inturn can ruin the livelihood of farmers (Sinha, 2002). Due to extreme weather events, rural households whose livelihood is heavily dependent on traditional rainfed agriculture mostly affected (Haile, 2005). Diversification of the farming activities can enhance the chances of coping up against the extreme weather events in the long run. On the other hand, understanding of the farmers' perceptions of weather and climate is a critical step to facilitate effective communication on science-based agrometeorological knowledge (ZumaNetshiukhwi et al., 2013). Several factors like farmsize, household income, etcshape farmers' perception (Allahyari et al., 2016).Quantitative data pertaining to farmers' perception about long term weather impact is scanty (Osgood et al., 2018). In the paper investigation was made on the variation in the levels of livelihood security and perception with respect to extreme weather events among the farmers engaged in different farming combinations to find out the best farming system combination which can provide better livelihood security as well as the relative psychological advantage to handle the extreme weather event situation in more proactive way.

\section{Materials and Methods}

The study was carried out in two blocks of Sundarbans region of West Bengal, namely; Kakdwip and Sagar (island). Three enterprise combination was considered for the study, they are as follows:

Enterprise option 1
Husbandry+ Horticulture

Enterprise option 2 (EO- 2): Animal Husbandry+ Fisheries

Enterprise option 3 (EO-3): Animal Husbandry + Crop farming (Other than horticultural crops)

From each block twenty five respondents from each enterprise combination was randomly selected. Thus from each block 75 respondents (25 respondents from each of enterprise combination) was selected, hence total respondents from the two blocks were 150. One livelihood security Index was developed for the study by involving the parameters like Nutritional security, Economic Security, Health security, Social Security, Educational security, Institutional Security, Infrastructural security. Under each parameters there were a different number of items for measuring the parameters; like for measuring Nutritional security there were 17 items, for Economic Security there were 21 items, for Health security there were 18 items, for Social Security there were 15 items, for Educational security there were 13 items, for Institutional Security there were 11 items and Infrastructural security there were 15 items. The score of the respondents with respect to livelihood security was analyzed by adding the score of each parameter. The respondents were categorized on the basis of Livelihood Security score as low (Livelihood Security Scores $<77.35$ ), medium (Livelihood Security Scores $=77.35-86.45$ ) and high (Livelihood Security Scores $>>86.45$ ) on the basis of mean and standard deviation. One 'Perception Index' was also developed under the study by incorporating 10 statements, each statement was measured by using 5 dimensions namely: Strongly agree, Agree, Neutral/ Can't say, Disagree, Strongly disagree. After adding the 
score of the statement the perceptual level of the respondents were measured. The respondents were categorized on the basis of perception score as low (Perception level Scores $<79.70$ ), medium (Perception level Scores $=79.70-89.52$ ) and high (Perception level Scores > 89.52) on the basis of mean and standard deviation. The data was analyzed by using SPSS 20 statistical package.

\section{Results and Discussion}

Table 1 depicts the distribution of respondents who were practicing different farming combinations in different categories, according to livelihood security level scores and perception level scores. There was a significant relationship between livelihood security score and different farming combinations as the Pearson Chi-square value was 156.25 which was significant at 1 percent level of significance. The table 1 also suggest that animal husbandry and horticulture enterprise combinations generated medium level of livelihood security among 46 respondents or 92 percent of the respondents who were following the enterprise combination and only 8 percent of the respondents (4 respondents)fell in high livelihood security category. From the table it can be said that among all the respondents following different enterprise combination, only the respondents who were following animal husbandry and horticulture combination fell in the high livelihood security levels score category (4 respondents out of the 150 respondents). Those farmers who were following animal husbandry and crop farming combination, all of them fell in low livelihood security levels score category. This suggested that, farmers who are following animal husbandry and horticulture combinations were more secure in terms of livelihood security. On the other hand, if we consider the chi-square value of 244.29 (significant at $1 \%$ level of significance) which suggested the significant relationship among perception level scores and different farming combination level. From the table 1, it can be said that all the respondents who were practicing animal husbandry and horticulture combination fell in high perception level score whereas only one respondent who was practicing animal husbandry and fisheries farming combination fell in high perception level score. Majority of the farmers (40 out of 50 respondents) fell in low perception level category who were practicing animal husbandry and crop farming enterprise. The table also suggested that farmers with animal husbandry and horticulture enterprise background had a high level of perception score as well as medium to high level of livelihood security score, on the contrary farmers who were practicing animal husbandry and crop farming fell in low livelihood security category, as well as in low perception level score category. Generally small farmers with limited resources, knowledge, expertise and exposure practiced the animal husbandry and crop farming enterprise combination. As opined by Swaminathan and Rengalakshmi (2016), livelihood options for small scale farmers are severely affected by extreme weather events, thus special attention should be provide to that category of the farming community. The findings of the study implied that, in the study area animal husbandry and horticulture farming combination gave the best possible result in addressing the problems related to extreme weather events condition.

The perusal of the table 2 revealed that animal husbandry and horticulture enterprise combination gave the highest livelihood security level score and highest perception level score on the other side animal husbandry and crop farming gave the lowest score pertaining to a livelihood security level as well as perception level. From the table it can be said that, there was significant variation 
among the livelihood security scores of farmers who were following different farming combination in the study area. Similar result was also observed in case of perception level score as the F-value was 655.89 which was significant at 1 percent level of significance which suggested that there was a significant variation among different enterprise combination in terms of perception score.

Table.1 Enterprise wise distribution of respondents according to Livelihood security and perception level scores

\begin{tabular}{|c|c|c|c|c|c|c|c|c|}
\hline \multirow[t]{2}{*}{$\begin{array}{l}\text { Farming } \\
\text { combinations }\end{array}$} & \multirow[t]{2}{*}{ Parameters } & \multicolumn{3}{|c|}{$\begin{array}{l}\text { Livelihood security } \\
\text { level(LSL)Scores }\end{array}$} & \multicolumn{3}{|c|}{ Perception level (PL) Scores } & \multirow[t]{2}{*}{ Total } \\
\hline & & $\begin{array}{c}\text { Low } \\
(<77.35)\end{array}$ & $\begin{array}{c}\text { Medium } \\
(\mathbf{7 7 . 3 5 -} \\
\mathbf{8 6 . 4 5 )}\end{array}$ & $\begin{array}{c}\text { High } \\
(>86.45)\end{array}$ & $\begin{array}{c}\text { Low } \\
(<79.70)\end{array}$ & $\begin{array}{c}\text { Medium } \\
\text { (79.70- } \\
\text { 89.52) }\end{array}$ & $\begin{array}{c}\text { High } \\
(>89.52)\end{array}$ & \\
\hline \multirow{2}{*}{$\begin{array}{l}\text { Animal } \\
\text { Husbandry+ } \\
\text { Horticulture }\end{array}$} & Count & 0 & 46 & 4 & 0 & 0 & 50 & 50 \\
\hline & $\begin{array}{l}\% \text { within } \\
\text { enterprise }\end{array}$ & 0.00 & 92.00 & 8.00 & 0.00 & 0.00 & 100.00 & 100.00 \\
\hline \multirow{2}{*}{$\begin{array}{l}\text { Animal } \\
\text { Husbandry + } \\
\text { Fisheries }\end{array}$} & Count & 0 & 50 & 0 & 0 & 49 & 1 & 50 \\
\hline & $\begin{array}{l}\% \text { within } \\
\text { enterprise }\end{array}$ & 0.00 & 100.00 & 0.00 & 0.00 & 98.00 & 2.00 & 100.00 \\
\hline \multirow{2}{*}{$\begin{array}{l}\text { Animal } \\
\text { Husbandry + } \\
\text { Crop farming }\end{array}$} & Count & 50 & 0 & 0 & 40 & 10 & 0 & 50 \\
\hline & $\begin{array}{l}\% \text { within } \\
\text { enterprise }\end{array}$ & 100.00 & 0.00 & 0.00 & 80.00 & 20.00 & 0.00 & 100.00 \\
\hline \multirow[t]{2}{*}{ Total } & Count & 50 & 96 & 4 & 40 & 59 & 51 & 150 \\
\hline & $\begin{array}{l}\% \text { within } \\
\text { enterprise }\end{array}$ & 33.30 & 64.00 & 2.70 & 26.70 & 39.30 & 34.00 & 100.00 \\
\hline \multicolumn{2}{|c|}{ Pearson Chi-Square } & \multicolumn{3}{|c|}{$156.25 *$} & \multicolumn{4}{|c|}{$244.29 *$} \\
\hline
\end{tabular}

* Significant at 1 percent level of significance

Table.2 Descriptive statistics of differential livelihood security level and perception level with respect to different enterprise combination

\begin{tabular}{|l|c|c|}
\hline Farming combinations & $\begin{array}{c}\text { Livelihood security level } \\
\text { Scores } \\
\text { (Mean } \pm \text { SEM) }\end{array}$ & $\begin{array}{c}\text { Perception level scores } \\
\text { (Mean } \pm \text { SEM) }\end{array}$ \\
\hline $\begin{array}{l}\text { Animal Husbandry + } \\
\text { Horticulture }\end{array}$ & $86.76^{\mathrm{a}} \pm .21$ & $90.40^{\mathrm{a}} \pm .15$ \\
\hline $\begin{array}{l}\text { Animal Husbandry + Fisheries } \\
\text { Animal Husbandry+ Crop } \\
\text { farming (Other than } \\
\text { horticultural crops) }\end{array}$ & $82.74^{\mathrm{b}} \pm .16$ & $84.40^{\mathrm{b}} \pm .16$ \\
\hline Total & $76.18^{\mathrm{c}} \pm .14$ & $79.04^{\mathrm{c}} \pm .31$ \\
\hline F value & $81.89 \pm .37$ & $84.61 \pm .40$ \\
\hline
\end{tabular}

* Significant at 1 percent level of significance

Different Superscripts $(a, b, c)$ indicates significant levels of difference 
Table.3 Distribution of farmers according to differential perception level vis-à-vis livelihood security

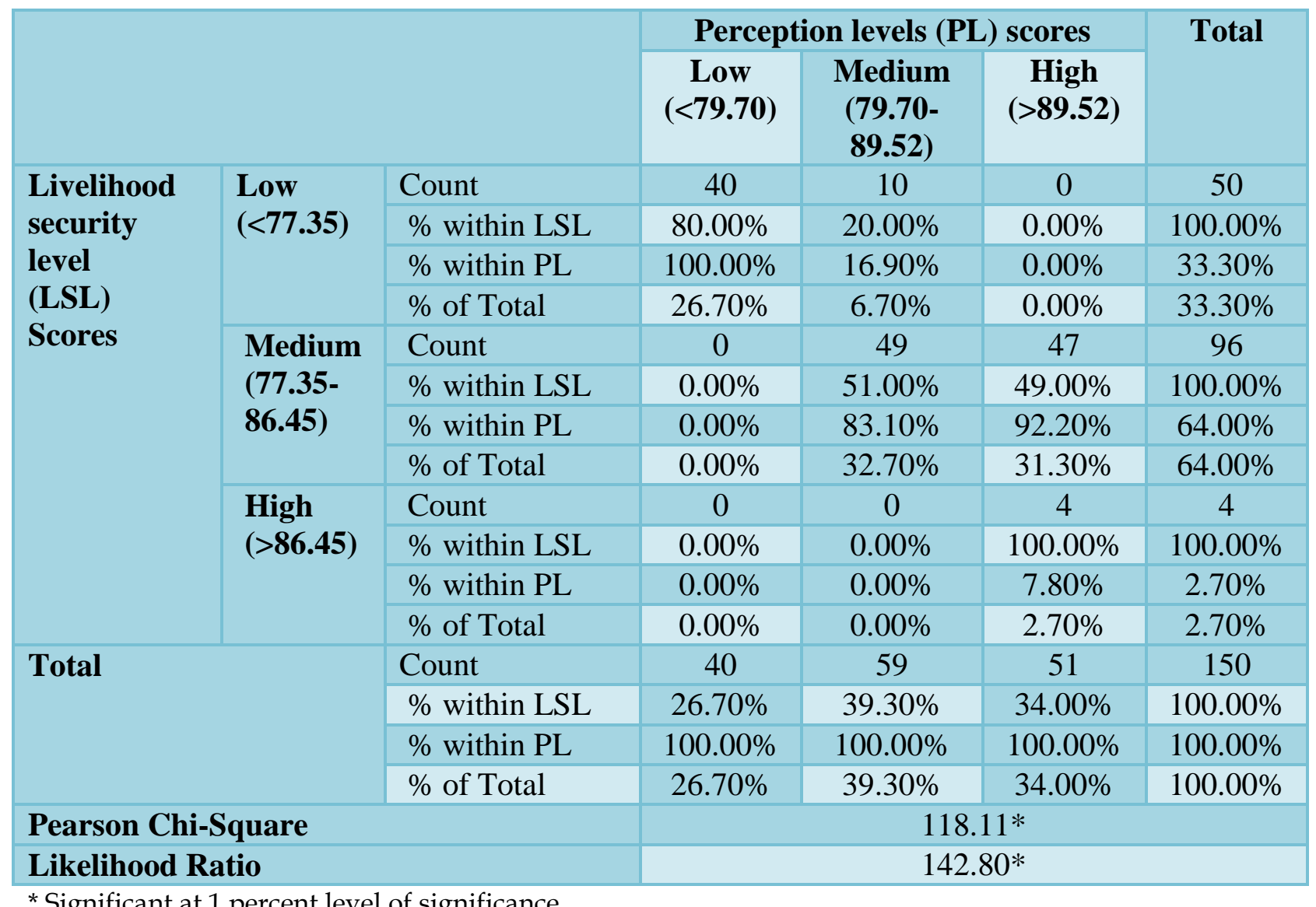

* Significant at 1 percent level of significance

Table.4 Correlation between the scores of livelihood security and perceptual index

\begin{tabular}{|l|l|c|c|}
\hline \multicolumn{2}{|c|}{} & \multicolumn{1}{c|}{$\begin{array}{c}\text { Livelihood } \\
\text { security } \\
\text { Level Scores }\end{array}$} & $\begin{array}{c}\text { Perception level } \\
\text { scores }\end{array}$ \\
\hline \multirow{2}{*}{ Kendall's tau_b } & Livelihood security Level Scores & 1.000 & $.872^{*}$ \\
\cline { 2 - 4 } & Perception level scores & $.872^{*}$ & 1.000 \\
\hline \multirow{2}{*}{ Spearman's rho } & Livelihood security Level Scores & 1.000 & $.950^{*}$ \\
\cline { 2 - 4 } & Perception level scores & $.950^{*}$ & 1.000 \\
\hline
\end{tabular}

* Significant at 1 percent level of significance

Overall analysis suggested that, animal husbandry and horticulture enterprise combination gave the highest level of perception and livelihood score as the farmers engaged in that combination of enterprise were gaining more by selecting that combination which gave them extra mental strength to fight against the extreme weather events. On the contrary animal husbandry and crop farming gave the lowest livelihood security score which resulted in low perception level score and the farmers who were practising that combination of enterprise became the most vulnerable against the extreme weather event situation. 
From the study it can be recommended that animal husbandry and horticulture faming combination may be strengthened in the study area to boost the morale of the farming community to fight against the consequences of extreme weather events as well as to improve the livelihood security status.

Relationship among livelihood security level score as well as the perception level score is explained in the table 3. From the table it can be seen that 80 percent of the respondents in low livelihood security score fell in low perception level score. Similarly, all the respondents who fell in high level of livelihood security level score fell in high perception level score, also. This suggested that, there was a significant relationship among livelihood security and perception level of farmers. This fact can be proved by the fact that the Pearson Chi square value was 118.11 which was significant at 1 percent level of significance, which means there was a strong association among livelihood security level scores as well as perception level scores. Planned adaptation aimed at a larger scale and longer duration is necessary to sustain the livelihood security of small-holder farmers (Paudel et al., 2014). These planned adaptation strategies should be commensurate with the perception level of the farmers. From the study, it can be concluded that, to increase the perception of farmers in positive direction their livelihood security must be ensured. Farmers who perceive climate change based on affective impression and direct personal experience are more likely to suffer cognitive bias in their perceptions compared to farmers who perceive climate risk based on knowledge and analytic processing of climate information (Patrick et al., 2017). In other words, to increase the morale of the farming community for fighting against the extreme weather events their livelihood security should be improved.

Table 4 depicts the correlation among the scores of livelihood security and perceptual level. From the table, it can be said that livelihood security scores and perception level scores are highly correlated. Kendall tau value of 872 indicates the high level of correlation among these variables.

Similarly spearman rho value of. 950which is significant at 1 percent level of significance suggested that high level of correlation among livelihood security level scores and participation level scores. With the increase in perception level score the livelihood security score also increased. The respondents with good livelihood score perceived the difficulties of extreme weather events and took corrective actions, well in advance, which in-turn help them to maintain their livelihood in extreme weather conditions.

From the study it was found that, respondents who were following different enterprise combinations, had different level of livelihood security score as well as perception towards extreme weather events. Among different combination of enterprises animal husbandry and horticulture enterprise combination gave the best livelihood security score as well as the highest perception score. Practicing profitable enterprise not only secured the livelihood of farming community but also affected their perception towards the extreme weather events.

More positive perceptual level helps them to secure livelihood even in challenging extreme weather event situation. Like the farmers of Sundarbans other places which are continuously facing challenging weather situations, should choose suitable enterprise combinations which can help them to secure livelihood on sustainable basis. This can also help them to face extreme weather situations with more positive set of mind.

\section{Acknowledgement}

The study was conducted by the funding support from Indian Council of Social Science Research (ICSSR) and MHRD (Ministry of Education)through Impactful Policy Research in Social Science (IMPRESS) scheme under the sanctioned project entitled 'Formulating coping up strategies for extreme weather events in Sundarbans region through livestock based 
Integrated Farming System: A societal perspective'.

\section{References}

Allahyari, M., Ghavami, S., Daghighi Masuleh, Z., Michailidis, A., Nastis, S. 2016. Understanding Farmers' Perceptions and Adaptations to Precipitation and Temperature Variability: Evidence from Northern Iran. Climate. 2016 (4): 58

Haile, M. 2005. Weather patterns, food security and humanitarian response in subSaharan Africa. Philosophical Transactions of the Royal Society B. 360: 2169-2182

Hitayezu, P., Wale, E. and Ortmann, G. 2017. Assessing farmers' perceptions about climate change: A double-hurdle approach. Climate Risk Management. 17(2017): 123-138

Mohammad, A. and Chatterjee, A. 2018. Decoding Resilience Status of Dairy Farmers against Extreme Weather Events:A Demographic Perspective. Journal of Animal Research. 8 (5): 885890.

Mohammad, A., Chatterjee, A., Bhakat, C. and Dutta, S. 2018. Determining the Dimensions Affecting Resilience Status of Livestock Farmer against Extreme Weather Events by Developing One Resilience Scale. International Journal of Current Microbiology and Applied Sciences. 7(01): 3247-3253.

Osborne, R. and Evans, N. 2019. Friend or foe? UK farmers' relationships with the weather. Journal of Rural Studies. 72(2019): 205-215

Osgood, D., Powell, B., Diro, R., Farah, C.,
Enenkel, M., Brown, M.E., Husak, G., Blakeley, S.L., Hoffman, L. and McCarty, J.L. 2018. Farmer Perception, Recollection, and Remote Sensing in Weather Index Insurance: An Ethiopia Case Study. Remote Sensing. 10(12): 1887.

Paltasingha, K. R. and Goyarib, P. 2015. Climatic risks and household vulnerability assessment: a case of paddy growers in Odisha. Agricultural Economics Research Review, 28, (Conference), Pp. 199-210

Patel, S.K., Mathew, B., Nanda, A., Pati, S. and Nayak, H. 2019. A review on extreme weather events and livelihood in Odisha, India. Mausam. 70 (3): 551-560

Paudel, B., Acharya, B.S., Ghimire, R., Dahal, K.R. and Bista, P. 2014. Adapting Agriculture to Climate Change and Variability in Chitwan: Long-Term Trends and Farmers' Perceptions. Agricultural Research. 2014 (3): 165174

Sinha, A. 2002. Report on recovery and reconstruction following theOrissa super cyclone in October 1999, Asian Disaster Reduction Centre, 1

Swaminathan, M.S. and Rengalakshmi, R. 2016. Impact of extreme weather events in Indian Agriculture: Enhancing the coping capacity of farm families. Mausam. 67 (1): 1-4

Zuma-Netshiukhwi, G., Stigter, K. and Walker, S. 2013. Use of Traditional Weather/Climate Knowledge by Farmers in the South-Western Free State of South Africa: Agrometeorological Learning by Scientists. Atmosphere. 4(4): 383-410.

\section{How to cite this article:}

Asif Mohammad and Anupam Chatterjee. 2020. Livelihood Security Vis-à-Vis Perception towards Extreme Weather Events among Farmers Engaged in Different Farming Enterprises in Sundarbans Region of India. Int.J.Curr.Microbiol.App.Sci. 9(12): 1092-1098. doi: https://doi.org/10.20546/ijcmas.2020.912.131 